\title{
Neuropsychological and psychopathological variables modulating cognitive insight in people with schizophrenia
}

\author{
Miguel Simón-Expósito ${ }^{1}$, and Elena Felipe-Castaño ${ }^{2 *}$ \\ 1 Clinical Psychology. Group 5 Action and Social Management. Madrid (Spain) \\ 2 Lecturer in Personality, Assessment and Psychologycal Intervention. Faculty of Teacher Trainning. University of Extremadura. Cáceres (Spain)
}

\begin{abstract}
Título: Variables neuropsicológicas y psicopatológicas moduladoras del insight cognitivo en personas con esquizofrenia.

Resumen: El insight cognitivo es la capacidad de los pacientes con esquizofrenia de evaluar sus experiencias psicóticas y responder a la retroalimen tación correctiva. Su relación con el funcionamiento neuropsicológico y la modulación que ejercen el estado de ánimo y la ansiedad están aún poco claras. Avanzar y profundizar en su conocimiento tendría un impacto importante sobre la comprensión de los mecanismos cognitivos y los programas de intervención. Se seleccionaron dos muestras, muestra clínica, con personas con esquizofrenia $(n=43)$, muestra personas sanas $(n=50)$, a las que se aplicó la Escala de insight cognitivo (EICB), una batería neuropsicológica y cuestionarios de depresión y ansiedad. Los resultados sugieren una influencia de la ansiedad y de los déficits de flexibilidad cognitiva en el desarrollo de los mecanismos de la Auto-Reflexión en personas con esquizofrenia, con un patrón diferente al encontrado en personas sanas. Se discuten los resultados con respecto a los programas de intervención.

Palabras clave: Insight cognitivo. Déficit neurocognitivo. Metacognición. Esquizofrenia. Ansiedad. Depresión.
\end{abstract}

\section{Introduction}

One of the characteristics present in many persons with schizophrenia is the lack of any understanding of their illness and the lack of awareness that they are suffering from a psychiatric disorder. This has been called insight (Amador \& David, 1998) and has consequences for the evolution and prognosis of the illness (Drake et al., 2007). However, in many patients, an increase in knowledge concerning their disorder is often not accompanied by a change in their way of thinking.

For Beck \& Warman (2004), the patient's crucial cognitive problem is their attenuated capacity to evaluate their anomalous experiences and to recognise that their conclusions are incorrect, which influences the development of delusional thoughts and beliefs. They therefore develop the concept of cognitive insight, understood as a metacognitive type process based on the individual's capacity to distance themselves from their erroneous beliefs and to make a corrective evaluation of their own interpretations, using external feedback. The Cognitive Insight Scale (CIS) was created in order to measure this process. It is made up of two subscales: the first is Self-Reflection (SR), defined as the capacity for introspection, openness to corrective feedback from others and to generate new explanatory hypotheses of the phenomena; while the second is Self-Certainty (SC), the degree

* Correspondence address [Dirección para correspondencia]: Elena Felipe-Castaño (Ph.D), Faculty of Teacher Trainning, Campus universitario, s/n, 10073, Cáceres (Spain). E-mail: efelipe@unex.es (Article received: 1-3-2021, revised: 1-4-2021, accepted: 14-9-2021)
Abstract: Cognitive insight is the capacity of patients with schizophrenia to evaluate their psychotic experiences and respond to the corrective feedback. The relationship with their neuropsychological functions and the modulation exercised by mood and anxiety are still not clear. To make advances and deepen our knowledge would have an important impact on our understanding of the cognitive mechanisms and intervention programmes. Two samples were chosen, one clinical with persons suffering from schizophrenia $(n=43)$ and another with healthy individuals $(n=50)$. The Cognitive Insight Scale (BCIS), a neuropsychological battery and questionnaire concerning depression and anxiety, was applied to them. The results suggest an influence of anxiety and the deficits in cognitive flexibility on the development of the mechanisms of Self-Reflection in persons with schizophrenia, with a different pattern to that found in healthy individuals. The results are discussed with respect to the intervention programmes.

Keywords: Cognitive insight. Neurocognitive deficit. Metacognition. Schizophrenia. Anxiety. Depression.

to which the subject is firmly convinced of the correctness of their beliefs (Beck et al., 2004).

Various studies have confirmed the association found by Beck et al. (2004) between low positive levels of symptomatology of SR and high levels of SC (Van Camp et al., 2017). However, it should also be said that not all studies have confirmed this (Penney et al., 2018).

Similarly, the findings suggest that the deficits in cognitive insight could be related to deficits in such basic neurocognitive functions as memory and verbal learning (Buchy et al., 2010; Engh et al., 2011), or attention span and mental flexibility (Lysaker \& Buck, 2008). Nevertheless, only three out of the thirty papers reviewed by Van Camp et al. (2017) found a positive relation between high levels of SR and a better neurocognitive performance, while the majority of the studies found a negative relation with SC.

The results concerning verbal memory are based on the fact that cognitive insight rests upon the necessity for available information and searching through recent memories as the basis for self-monitoring (Orfei et al., 2010). As for the executive functioning, the focus has been on the measures to change the mindset and error monitoring (Srivastava \& Kumar, 2016), demonstrating a significant association between the levels of SC and the non-perseverative errors of the Wisconsin Card Sorting Test (WCST) (Orfei et al., 2010).

Despite the studies carried out concerning cognitive insight in healthy subjects, some authors consider that there is no evidence to support the idea that the concept is applicable to subjects with and without psychosis (Van Camp et al., 2017). In non-clinical samples, the works suggest a higher level of cognitive insight, with a tendency towards higher SR 
and lower SC (Warman \& Martin, 2006), which would be related to a worse performance in tasks that require memory and of an executive nature (Orfei et al., 2011). The same happens to the consistent relationship found between the capacity for SR and the levels of anxiety and depression in clinical samples (Palmer et al., 2015), which requires a greater contrast in non-clinical samples in order to advance in the study of its modulating mechanism.

The appearance of intervention programmes, such as the Metacognitive Training Program (Moritz \& Woodward, 2007), with promising results as far as improving the cognitive insight of patients with schizophrenia goes (Birulés et al., 2020; Simón-Expósito \& Felipe-Castaño, 2019), means that it is essential to make advances in the relationship between the said variables, given that some studies have found increasing levels of depression in patients in line with increases in their cognitive insight as a consequence of the psychotherapeutic treatment (Granholm et al., 2005).

Ultimately, the relationships between the way of thinking that underlies the concept of cognitive insight and neuropsychological functioning and the modulating effects of anxiety and mood on the said concept are still unclear. Analysing this relationship separately for the indices of SR and SC, in both persons with schizophrenia and healthy controls, could, we believe, contribute to our understanding of these concepts in psychotic disorders.

To do so, in this work, our objective is to analyse the relation between cognitive insight, neurocognitive performance, mood and anxiety in personas with schizophrenia and the differences with a sample of persons with no diagnosis of a mental disorder. According to these objectives, we can state the following hypotheses: a) The sample of persons with diagnosed schizophrenia will show higher levels of SC and lower levels of SR than those controls with no diagnosis; b) We shall find a positive relationship between the levels of SR and those of mood and anxiety; c) In persons with schizophrenia, we shall find a positive relationship between the levels of SR and the neurocognitive performance; while in the healthy control group this relation will be negative, and d) In persons with schizophrenia, we shall find a negative re- lation between the levels of SC and the neurocognitive performance; while in the healthy control group this relation will be positive.

\section{Method}

\section{Participants}

The total number of participants was 93 subjects, 43 $(46 \%)$ in the clinical sample and 50 in the non-clinical sample. The sample of persons with schizophrenia was recruited in Psychosocial Rehabilitation Centres (CRPS) and in supervised housing of the public services for attention to patients with serious mental disorders in the Region of Extremadura. We included in the study only those patients who had a specific diagnosis of schizophrenia according to the DSM-V criteria and who had shown a clinical stability of at least three months, defined as the absence of any substantial modification in treatment, admittance to hospital for any psychopathological destabilisation or consultation in hospital emergency services.

The non-clinical sample was selected from among the students and staff at the University of Extremadura. We excluded those persons who stated they had been diagnosed with some psychiatric disorder, those who were being treated for a mental disorder or who had a family history of psychosis up to the first degree of consanguinity. The sociodemographic and clinical characteristics of both samples can be seen in Table 1.

We excluded from both samples those persons who had had a prior neurological disorder or brain trauma with loss of consciousness and we selected only those subjects between 18 and 65 years of age with a completed level of studies over eight years.

The samples differed significantly in the variables of gender and years of study. For that reason, a statistical control of the said variables was carried out. Only the variable of age had a normally adjusted distribution.

Table 1

Clinical and sociodemographic characteristics of the samples of participants.

\begin{tabular}{|c|c|c|c|c|c|c|c|c|c|c|}
\hline & \multicolumn{3}{|c|}{ Non-clinical sample, $n=50$} & \multicolumn{3}{|c|}{ Clinical sample, $n=43$} & \multicolumn{3}{|c|}{ Total, $n=93$} & \multirow[b]{2}{*}{$t(\operatorname{Sig})$} \\
\hline & $M$ & $D T$ & Range & $M$ & $D T$ & Range & $M$ & $D T$ & Range & \\
\hline$\overline{\text { Age }}$ & 39.14 & 14.70 & $19-65$ & 38.21 & 9.58 & $20-62$ & 38.71 & 12.53 & $19-65$ & $0.366(.715)$ \\
\hline Years of study & 14.34 & 3.931 & $10-20$ & 11.51 & 3.042 & $8-20$ & 13.03 & 3.803 & $8-20$ & $-3.906(.000)$ \\
\hline Age at start of illness & & & & 23.07 & 6.912 & $12-38$ & & & & \\
\hline Duration of illness & & & & 14.81 & 7.848 & $2-32$ & & & & \\
\hline Hospital admissions & & & & 2.17 & 2.208 & $0-9$ & & & & \\
\hline & \multicolumn{3}{|c|}{ Men/women (\%) } & \multicolumn{3}{|c|}{ Men/women (\%) } & \multicolumn{3}{|c|}{ Men/women (\%) } & $\chi^{2}$ (Sig.) \\
\hline Gender & \multicolumn{3}{|c|}{$15 / 35(30 / 70)$} & \multicolumn{3}{|c|}{$35 / 8(81 / 19)$} & \multicolumn{3}{|c|}{$50 / 43(54 / 46)$} & $24.566(.000)$ \\
\hline
\end{tabular}

Note: ${ }^{a}$ Age at first hospital admittance or at start of positive or negative symptoms that predicted it. 


\section{Instruments}

\section{Evaluation of Cognitive Insight}

Beck's Cognitive Insight Scale (BCIS, Beck et al., 2004) in its Spanish adaptation by (Gutiérrez-Zotes et al., 2012). This is a self-reporting scale of 15 items, each with four response intervals, from 0 (totally disagree) to 3 (totally agree). It measures cognitive insight in its SR and SC dimensions. It also calculates a Composite Index, subtracting the SC score from the SR score. With our participants, we obtained $a$ of 0.68 and 0.60 , respectively, similar to the original version of the instrument.

\section{Neurocognitive evaluation}

We looked for a combination of tests that could be applied in a maximum time span of 35 to 45 minutes, taking as a reference the tests recommended by the MATRICS initiative (Nuechterlein et al., 2004) and those used to estimate concurrent validity in the validation of the Spanish version of the Brief Assessment in Cognition in Schizophrenia (BACS, Segarra et al., 2011). We selected the domains and instruments set out below:

Information processing speed: Number Key from the WAIS-IV scale.

Motor velocity. Token Motor Task, from the Spanish adaptation of the BACS.

Memory

Working memory: a) Immediate memory. Digit Span Test Sequencing from the WAIS-IV scale. b) Information maintenance and manipulation. Digit Span Test in Ascending Order, from the same scale. The Direct Score of the Span was used in both cases.

Verbal memory: Verbal Learning Test EspañaComplutense (TAVEC, Benedet \& Alejandre, 1998). The Immediate Free Memory task for the A List was applied. Following the oral presentation and over five trials, the subject must attempt to repeat all the words he/she remembers regardless of the order when each of the trials ends. The sum of the words correctly remembered in the five trials was taken as the measurement index.

Executive functions: a) Verbal fluency. This was measured through the capacity to generate words that start with a specific letter (FAS) within a certain time limit and the capacity to generate words that belong to a certain semantic category (Lezak, 1995). The total sum of correct words in both tests was used. b) Cognitive flexibility. This was measured using the WCST (Heaton et al., 1993). Of the multiple dimensions that are taken into account for the evaluation of the test results, we used the following: Percentage of Perseverative Errors, Percentage of Non-Perseverative Errors, Percentage of Responses on a Conceptual Level and Number of Classification Categories Completed. The Spanish version of the test published by TEA in 2010 was used.

\section{Clinical evaluation}

Beck Anxiety Inventory (BAI, Beck et al., 1988), in its Spanish version of the test (Sanz \& Navarro, 2003). In our sample, we found an internal consistency index through Cronbach's $a$ of 0.92 .

Beck Depression Inventory-II (BDI-II, Beck, Steer, \& Brown, 1996). We used the Spanish version of the BDI-II (Sanz et al., 2003). In our sample from the present study, we obtained an internal consistency coefficient through Cronbach's $a$ of 0.90 .

\section{Procedure}

In the case of the clinical sample, the resource directors selected the participants, checking the inclusion and exclusion criteria through the patients' clinical files. All the participants were informed both verbally and in writing of the aims of the research and their informed consent was obtained in writing, as well as that of their tutors in such cases where there existed legal incapacity. The evaluation was carried out in two individual sessions of forty five minutes, starting with the collection of the sociodemographic and clinical data. The neurocognitive battery was applied in the second session. All the patients were evaluated by their respective reference.

The non-clinical sample of persons was evaluated by post-graduate psychologists in training, under the supervision of the researcher.

The study obtained the approval of the Clinical Research Ethics Committee of the Health Services Area of Cáceres in accordance with the International Medical Code of Ethics of the WMA (Helsinki Declaration of 1975, revised in 2008).

\section{Data analysis}

Descriptive analyses and parameterisation tests were carried out. The contrast of differences in the average between the two groups was calculated using the Student $t$ test and the result of the Welch test if the variances turned out not to be homogeneous. In the case of significant differences, Cohen's $d$ statistic was calculated in order to estimate the size of the effect (Cohen, 1988). We also carried out a correlation analysis and a partial correlation analysis between the SR and SC variables and the variables under study, controlling the effect of the said variables on each other.

In order to generate explicative models of the relation between the variables of cognitive insight SR and SC and those of a clinical nature and neurocognitive performance, a Regression Analysis was used in steps for the variables that turned out to be significant in the correlation study described previously, using the F Probability $<=.050$ as the start criterion and the $F$ Probability $>=.100$ to finish.

All the analyses were carried out using the SPSS Statistics 21.0 and bilateral significance tests were used with a significance level of $5 \%$ and $1 \%$. 


\section{Results}

We found significant differences between the clinical and non-clinical samples in the results of several tests (Table 2). Thus, the clinical sample was characterised by higher levels in the SC scale, in the BDI-II scale and worse results in the
Verbal Memory test, in the Token Motor Task, in those of Verbal Fluency and in the Numbers Key. The clinical sample also showed a higher percentage of Perseverative Errors in the WCST and inferior results in the Percentage of Conceptual Level Responses and in the number of completed categories. The differences had high-size effects in all cases.

Table 2

Differences between the clinical and non-clinical samples. Student t test for independent samples.

\begin{tabular}{|c|c|c|c|c|c|c|c|c|c|}
\hline & \multicolumn{2}{|c|}{ Clinical sample } & \multicolumn{2}{|c|}{ Non-clinical sample } & \multicolumn{4}{|c|}{$t$ test for equality of measures } & \multirow[b]{3}{*}{ Cohen's $d$} \\
\hline & \multirow[b]{2}{*}{ M } & \multirow[b]{2}{*}{$D T$} & \multirow[b]{2}{*}{$M$} & \multirow[b]{2}{*}{$D T$} & \multirow[b]{2}{*}{$t$} & \multirow[b]{2}{*}{ Sig. (bilateral) } & \multicolumn{2}{|c|}{ Confidence interval } & \\
\hline & & & & & & & Inferior & Superior & \\
\hline$\overline{\mathrm{SR}}$ & 13.86 & 4.92 & 12.58 & 4.52 & 1.306 & .195 & -.667 & 3.228 & -0.27 \\
\hline SC & 9.02 & 3.01 & 7.26 & 3.32 & 2.663 & .009 & .448 & 3.079 & -0.55 \\
\hline GI & 4.84 & 5.99 & 5.32 & 5.59 & -.402 & .689 & -2.871 & 1.905 & \\
\hline Anxiety & 14.84 & 10.23 & 11.40 & 11.11 & 1.542 & .127 & -.991 & 7.865 & \\
\hline Depression* & 15.51 & 11.21 & 9.20 & 8.06 & 3.070 & .003 & 2.216 & 10.407 & -0.65 \\
\hline $\mathrm{VM}$ & 37.44 & 11.72 & 54.20 & 9.46 & -7.625 & .000 & -21.124 & -12.393 & 1.59 \\
\hline DDS & 5.67 & 1.28 & 6.04 & 1.16 & -1.441 & .153 & -.869 & .138 & \\
\hline IDS & 4.81 & 1.33 & 5.06 & 1.18 & -0.943 & 348 & -.765 & .272 & \\
\hline TMT & 73.63 & 13.43 & 90.86 & 8.78 & -7.418 & .000 & -21.846 & -12.618 & 1.54 \\
\hline SF & 16.81 & 4.87 & 23.76 & 5.54 & -6.372 & .000 & -9.111 & -4.781 & 1.33 \\
\hline FAS & 11.51 & 5.02 & 16.12 & 3.82 & -5.018 & .000 & -6.432 & -2.784 & 1.04 \\
\hline WAIS NK & 65.79 & 19.59 & 99.10 & 22.33 & -7.587 & .000 & -42.031 & -24.588 & 1.58 \\
\hline WCST PEP & 30.19 & 23.03 & 12.52 & 5.75 & 4.895 & .000 & 10.404 & 24.926 & -1.09 \\
\hline WCST NPEP* & 16.65 & 12.78 & 12.31 & 8.45 & 1.887 & .063 & -.246 & 8.924 & \\
\hline WCST CLRP* & 40.74 & 28.04 & 67.21 & 17.85 & -5.300 & .000 & -36.423 & -16.505 & 1.14 \\
\hline WCST CC* & 3.23 & 2.45 & 5.19 & 1.63 & -4.428 & .000 & -2.835 & -1.075 & 0.96 \\
\hline
\end{tabular}

*Equal variances are not assumed. Note: SR: Self-reflection; SC: Self-certainty; GI Global Index; VM: Verbal Memory; DDS Direct Digits Span; IDS: Increasing Digits Span; TMT: Token Motor Task; SF: Semantic Fluency; FAS; NK: Number Key; PEP: Perseverative Error Percentage; NPEP: Non-Perseverative Error Percentage; CLRP: Conceptual Level Response Percentage; CC: Categories Completed.

In the clinical sample, we found significant correlations between SR and the anxiety variable, but not in depression. We did not find significant relations with respect to any neurocognitive performance test, except with the WCST, in which significant correlations appear with all the variables, except for that of Non-Perseverative Errors. It is worth noting the negative relation found with respect to the Percentage of Perseverative Errors, of a moderate type $(r=-.484)$.

In the non-clinical sample, the SR variable correlates significantly with age and years of study, as well as with anxiety $(r=.421)$ and depression $(r=.406)$, which did not happen with the clinical sample. The same occurred with some neurocognitive performance tests, such as that of Verbal Memory $(r=.374)$, and with the Numbers Key test $(r=$ $.420)$, though the correlation was weak in both cases. Contrary to what occurred in the clinical sample, we found no correlations with any of the WCST scores.

As can be seen in the table, there are hardly any relations between the SC and the rest of the sociodemographic, clinical or neurocognitive performance variables studied.

Table 3

Bivariate correlation analysis.

\begin{tabular}{|c|c|c|c|c|c|c|c|c|c|c|c|c|}
\hline & \multicolumn{4}{|c|}{ TOTAL SAMPLE } & \multicolumn{4}{|c|}{ CLINICAL SAMPLE } & \multicolumn{4}{|c|}{ NON-CLINICAL SAMPLE } \\
\hline & \multicolumn{2}{|c|}{ SR } & \multicolumn{2}{|l|}{ SC } & \multicolumn{2}{|l|}{ SR } & \multicolumn{2}{|l|}{$\mathrm{SC}$} & \multicolumn{2}{|c|}{ SR } & \multicolumn{2}{|l|}{$\mathrm{SC}$} \\
\hline & Order zero & Partial & Order zero & Partial & Order zero & Partial & Order zero & Partial & Order zero & Partial & Order zero & Partial \\
\hline Age ${ }^{a}$ & $-.335 * *$ & & .052 & & -.214 & & .190 & & $-.376 * *$ & & .013 & \\
\hline Years of study a & $.251 *$ & & -.190 & & $.296^{2}$ & & .012 & & $.389^{* *}$ & & -.169 & \\
\hline Anxiety & $.387^{* *}$ & $.434 * *$ & -.021 & -.143 & $.322^{*}$ & $.445^{* *}$ & -.133 & -.120 & $.421^{* *}$ & $.451 * *$ & -.021 & -.108 \\
\hline Depression & $.278^{* *}$ & $.285 *$ & -.016 & $-.232 *$ & 0.134 & .241 & -.286 & -.312 & $.406^{* *}$ & $.354 *$ & .076 & -.114 \\
\hline VM & .166 & $.248 *$ & -.185 & $-.220 *$ & .277 & .336 & -.047 & -.107 & $.381^{* *}$ & $.374 * *$ & .000 & -.054 \\
\hline DDS & .086 & .108 & -.025 & .009 & .139 & .187 & -.041 & -.033 & .077 & .052 & .066 & .098 \\
\hline IDS & .180 & $.245^{*}$ & .048 & -.021 & .192 & .242 & $.322^{*}$ & $.311 *$ & .218 & .276 & -.134 & -.177 \\
\hline TMT & .050 & .115 & -.069 & -.064 & .235 & .244 & .014 & .030 & .085 & .104 & .270 & .277 \\
\hline $\mathrm{SF}$ & -.070 & .049 & -.090 & -.111 & .049 & .136 & .159 & .115 & -.029 & .039 & .017 & -.015 \\
\hline FAS & -.110 & -.052 & -.093 & -.111 & .100 & .091 & .111 & .077 & -.243 & -.205 & -.035 & -.055 \\
\hline WAIS NK & .170 & $.239 *$ & -.197 & $-.221 *$ & .220 & .267 & -.103 & -.157 & $.420^{* *}$ & $.412 * *$ & .004 & -.030 \\
\hline WCST PEP & $-.247^{*}$ & $-.356 * *$ & .202 & $.215^{*}$ & $-.484^{* *}$ & -.541 & .191 & .223 & -.118 & -.210 & -.129 & -.114 \\
\hline WCST NPEP & .050 & .021 & .116 & .120 & -.001 & .029 & .043 & .034 & .063 & -.028 & .106 & .116 \\
\hline WCST CLRP & .137 & $.233 *$ & $-.206 *$ & $-.219 *$ & $.374^{*}$ & .400 & -.161 & -.161 & .032 & .150 & -.020 & -.030 \\
\hline WCST CC & 0.162 & $.232 * *$ & -.104 & -.011 & $.384^{*}$ & .413 & -.101 & -.096 & .049 & .081 & .135 & .125 \\
\hline
\end{tabular}

Note : Spearman's Rho; See Table 2. ${ }^{*} p<.05 ;{ }^{* *} p<.001$ 
Taking into account the above data, the linear regression analysis of the sample of patients included the anxiety variable and all the variables of the WCST. Furthermore, taking into account the literature review, the variables of gender, age, years of study and depression were introduced because of their interest for the study (see Table 4).

Table 4

Regression analysis. Dependent V ariable $=S R$. Clinical sample.

\begin{tabular}{|c|c|c|c|c|c|c|c|c|c|}
\hline \multirow{2}{*}{ Model } & \multirow{2}{*}{$\frac{\mathrm{R}}{\text { Belonging to group }=\text { Patient }(\text { Selected })}$} & \multirow{2}{*}{$\mathrm{R}^{2}$} & \multirow{2}{*}{$\begin{array}{c}\mathrm{R}^{2} \\
\text { corrected }\end{array}$} & \multirow{2}{*}{$\begin{array}{c}\text { Typical Error } \\
\text { Estimation }\end{array}$} & \multicolumn{5}{|c|}{ Statistics of change } \\
\hline & & & & & Change in $\mathrm{R}^{2}$ & Change in $F$ & gl1 & $\mathrm{gl} 2$ & Sig. Change in $F$ \\
\hline 1 & $.484^{\mathrm{a}}$ & .234 & .215 & 4.364 & .234 & 12.512 & 1 & 41 & .001 \\
\hline 2 & $.605^{b}$ & .366 & .334 & 4.020 & .132 & 8.327 & 1 & 40 & .006 \\
\hline
\end{tabular}

The Percentage of Perseverative Errors of the WCST explains $23.4 \%$ of the variance of the SR in the group of patients $\left(21.5 \%\right.$ according to the corrected $\left.R^{2}\right)$ and $13.2 \%$ for Anxiety. In this group, there is a negative correlation with the Percentage of Perseverative Errors of the WCST $(r=-$ .484). If we eliminate from both the effect of the Anxiety variable, this correlation increases $(r=-.541)$. The variable Depression does not achieve an adequate level of significance to be considered.

Table 5

Regression analysis. Dependent Variable $=S R$. Non-clinical sample

\begin{tabular}{|c|c|c|c|c|c|c|c|c|}
\hline \multirow[b]{2}{*}{ Model } & \multirow{2}{*}{$\begin{array}{c}\mathrm{R} \\
\text { Belonging to group }= \\
\text { no diagnosis (Selected) }\end{array}$} & \multirow[b]{2}{*}{$\mathrm{R}^{2}$} & \multirow[b]{2}{*}{$\mathrm{R}^{2}$ corrected } & \multirow[b]{2}{*}{$\begin{array}{c}\text { Typical Error } \\
\text { Estimation }\end{array}$} & \multicolumn{4}{|c|}{ Statistics of change } \\
\hline & & & & & Change in $\mathrm{R}^{2}$ & Change in $F$ & gl1 gl2 & Sig. Change in $F$ \\
\hline 1 & $.421^{\mathrm{a}}$ & .177 & .160 & 4.145 & .177 & 10.326 & 148 & .002 \\
\hline 2 & $.539 \mathrm{~b}$ & .290 & .260 & 3.890 & .113 & 7.495 & 147 & .009 \\
\hline
\end{tabular}

Note: a. Predictor variables: (Constant), Anxiety; b. Predictor variables: (Constant), Anxiety, WAIS Number Key
In this case, we found two variables that explain in a significant way the changes in the said indicator. The first, Anxiety, explains $17.7 \%$ while the Numbers Key test explains $11.3 \%$, so together they explain $29 \%$ of the variance of the SR $\left(26 \%\right.$ according to the corrected $\left.R^{2}\right)$.

The direct correlation between SR and Anxiety is of $r=$ .421. When we eliminate from both the effect due to the variable Numbers Key, the relation decreases to $r=0.372$. In the case of the variable Numbers Key, its relation to the SR is practically the same as that of Anxiety $(r=.420)$, and if the effect of Anxiety is eliminated in both variables, then the correlation decreases to $r=.371$, which indicates a similar influence of both.

As for the SC, the correlation analysis carried out demonstrates that significant levels are only found for the clinical sample with the variable Span of the Increasing Digits test. When we apply the regression method by successive steps to the group of patients, this variable explains $10.3 \%$ of the variance of SC $(8.2 \%$ taking into account the corrected $R^{2}$ ). We found no collinearity between the independent variables in the regression analyses.

\section{Discussion}

This study aimed to analyse the differences in the profiles of cognitive insight between a sample of persons with schizo-
The correlation of SR with Anxiety is a positive type $(r=$ .322) and increases up to $(r=.415)$ on eliminating from both the effect due to the variable Percentage of Perseverative Errors.

For the regression analysis in the non-clinical sample, the variables Age, Years of Study, Anxiety, Depression, Verbal Memory and Numbers Key were introduced. The result posed the following explicative model (Table 5). phrenia and another of healthy controls, the impact of mood and anxiety on the subscales of SC and SR and the relation between both subscales and neurocognitive performance.

Our first hypothesis was that the clinical sample would show higher levels of SC and lower levels of SR than the non-clinical sample. In our results, the patients with schizophrenia show significantly higher levels of SC, but also higher levels of SR. These results contradict some previous findings (Giusti et al., 2013) and the initial hypothesis of Beck et al., (2004), although it seems that this relation would be established between patients with schizophrenia and delusional symptomatology (Van Camp et al., 2017), which may be why other studies have not been able to find such a pattern (Lincoln et al., 2014). This latter work found significantly higher levels of SR in a sample with similar characteristics to ours, of patients without active delusions and undergoing treatment. For the authors, habitual contact with therapists could be behind this increase in the levels of SR, as it enables the patients to develop a better capacity for introspection and an ability to communicate their thoughts as well as a greater acceptance of their contrast. This modulation is what has been called "socially ingenuous self-evaluation" (García Guerrero \& Lysaker, 2013) and, according to the authors, would serve to attenuate the risk factor of high levels of SC.

As for the high scores of SC, we cannot confirm their direct relation with delusional ideation. Although its active presence was a criterion for exclusion, we have not measured 
the degree of psychotic symptomatology or the predisposition to delusional ideation. Nevertheless, some authors have found higher levels of both SC and SR in healthy subjects with a predisposition to delusional ideation (Carse \& Langdon, 2013), which connects with the idea that psychotic experiences could form part of a continuum between normality and pathology (Johns \& van Os, 2001). Notwithstanding the controversial nature of this point of view, it could be said that such an excess of confidence in one's own beliefs would form part of a way of thinking present in persons with schizophrenia, irrespective of any delusional state. Such is the point of view of the research carried out by Moritz and his group, who also sustain that this cognitive style is the basis of the development and maintenance of delusional ideation (Moritz et al., 2005), through the "bias against the disconfirmatory evidence" (Woodward et al., 2006), or the presence of a great quantity of false memories, which such patients maintain with great assurance (Moritz \& Woodward, 2006). From this point of view, the SC and SR would be more closely linked to a way of thinking related to the capacity to consider more than one explanation, to generate explicative hypotheses, to adopt different perspectives, or to be able to reject one's own erroneous convictions than to psychopathology (Van Camp et al., 2017).

The sample of healthy controls presents a level of global cognitive insight which is practically the same as that of the patients with schizophrenia, but with significantly lower levels of self-confidence in their own beliefs and a lower capacity for self-reflection. For some authors (Orfei et al., 2011), this pattern could become adaptive, as it facilitates the taking of more effective decisions based on the avoidance of an excess of dithering and doubt (SC) and on the availability of effective tools for selecting and using the relevant information (SR). As with the group of Orfei et al. (2011), our results show that the same level of cognitive insight can be reached with the two different cognitive styles, so the explicative capacity of the global indicator is questionable (Van Camp et al., 2017) and reinforces the idea that it is more useful to study its dimensions as indicators of the styles of metacognitive thought.

As for the relation between cognitive insight and the clinical variables, the group of patients presents higher levels of depression than the healthy controls. Nevertheless, we found no relation between the levels of SR and mood, as we had postulated; while this relation was observed in the group of healthy persons. It has been suggested that this relation could be explained by the loss of conviction of the patients in their previous beliefs, upon understanding their psychotic experiences, which would lead to insecurity (Granholm et al., 2005) and to dithering, which typically appears in depressive thought patterns. Nevertheless, a weak relationship between cognitive insight and depression has been found in persons with schizophrenia (González-Blanch et al., 2014; Palmer et al., 2015).

In our participants, this worse state of mind is accompanied by higher levels of SR, although we cannot deduce an association between both. Previous studies have shown that the greater a person's depressive state, the closer the relation will be with the SR (Van Camp et al., 2017). For this reason, some authors suggest that the SR could be adaptive up to a point from which it could be associated with depressive thought patterns (Warman et al., 2007). The levels of depression in our participants were maintained between light and moderate, so psychotherapeutic intervention could act as a modulating element.

With respect to anxiety, it would seem to have a greater influence than depression on the levels of SR in the sample of patients; while in the group of healthy persons, the positive relation between the levels of anxiety and the SR index is even higher.

Our results for the population with schizophrenia are similar to those found in similar samples and are explained by a similar mechanism to that of depression in that it improves the capacity to recognise the illness (Colis et al., 2006). The relation between the levels of anxiety and depression found support this standpoint (Rathee et al., 2018). The contradictory process experienced by the patients between the emergency of an adequate explanation for their illness, derived from corrective information, and the firm maintenance of their erroneous beliefs, could explain this relationship. In any case, the degree of mutual influence and the mechanism that first sets it off are unknown.

In the healthy individuals, the process of selfstigmatisation is not present so, in the absence of specific studies, the explanation for the close relation between SR and anxiety could be due to the consolidated explicative models of anxiety themselves, such as those of the Cognitive Attention Syndrome (Wells \& Matthews, 1994), which is similar to the rumination (Carse \& Langdon, 2013) that shares similarities with SR.

A worse neurocognitive performance of the group of patients with respect to the healthy control group was expected in practically all the dimensions evaluated. However, contrary to the hypothesis, the results demonstrate the relation that exists between SR and the results of the WCST, which contradicts previous results (Nair et al., 2014). To be precise, the greatest correlations occur with the Perseverative Errors Index and the Percentage of Conceptual Level Responses and of Completed Categories, which reflects two kinds of difficulty: those concerning the incapacity to change category when the information of the context tells us that our responses are incorrect and those related to the conceptual establishment of categories.

In patients with schizophrenia, it has been demonstrated that they have a worse cognitive performance when faced with such tasks as those of the WCST, which require a high attention demand and the use of controlled resources (RuizVargas, 1987). These deficits could lead to a saturation of the voluntary control mechanisms, in line with the deterioration in the voluntary action that (Frith, 1995) considers to be one of the central cores of schizophrenia, and which would cause problems at the time of generating hypotheses concerning 
alternative categories and subjecting them to corrective verification and problems of inhibition.

The SR is considered a metacognitive process related to the capacity to think about one's own feelings and thoughts. This in turn implies being able to discriminate between oneself and others and the sense of control over one's thoughts and actions (Dimaggio et al., 2009). In schizophrenia, this capacity is affected and it is believed that the principal reason is the lack of mental flexibility, which hinders the ability to consider different perspectives and alternative hypotheses concerning events, strange ideas, wrong perceptions, beliefs and biases, as well as making complex inferences concerning oneself which could lead to a deficient insight (Pijnenborg et al., 2011).

We did not find in our results that this deficit was related to the difficulties of memory, as suggested by the work of Orfei et al. (2013). We understand that the difficulties of cognitive flexibility found in the patients are closer to the definition of SR, so our results are coherent with the said definition.

The difficulties in establishing categories for the patients reflect the problems of extracting abstract thought from situations in order to stimulate a concept applicable to the rest of the task. We believe that the specific deficits in verbal memory or motor speed do not justify these difficulties and we consider they would be better explained through the generalised cognitive deficits present in patients that evolve over a long period of time (González-Blanch et al., 2014; SimónExpósito \& Felipe-Castaño, 2018; Sponheim et al., 2010).

In the healthy individuals, our results point to the important role played by the availability, the capacity to manipulate and the speed of processing information in the development of an adequate SR capacity, which is not corroborated by the study of Orfei et al., (2011). The lack of any relation of this index with the indicators of the WCST used, as opposed to what happens in the sample of persons with schizophrenia, suggests the participation of different explicative mechanisms of the SR in both groups.

Finally, we have not been able to confirm the negative relation found by other authors between the levels of SC and the variables of neurocognitive functioning of the patients with schizophrenia, such as verbal memory (Engh et al., 2011) or cognitive flexibility (Srivastava \& Kumar, 2016). We only found a relation between working memory and the said dimension, which may be indicating that the availability of information and its manipulation, in the absence of the capacity to generate alternative explicative hypotheses, only

\section{References}

Amador, X. F., \& David, A. (1998). Insight and psychosis. Oxford University Press.

Beck, A. T., Baruch, E., Balter, J. M., Steer, R. A., \& Warman, D. M. (2004). A new instrument for measuring insight: The Beck Cognitive Insight Scale. Schizophrenia Research, 68(2-3), 319-329. https://doi.org/10.1016/S0920-9964(03)00189-0 contributes to a greater increase in one's own convictions, contrary to the opinion of other authors who understand that this would facilitate the updating of the errors and would increase their predisposition to accept inconsistencies.

In line with other similar works (Buchy et al., 2015), in our sample of healthy persons, we did not find relations between the SC index and the neurocognitive variables, so other variables not studied in this work, such as personality factors, could be modulating the degree of conviction in their beliefs in a similar way to that set out in the studies of persons with a tendency towards delusions (Weintraub \& Weisman de Mamani, 2015).

As a conclusion, we found differences between the clinical and the non-clinical participants in SR and SC, but not in the level of global cognitive insight. The presence of anxiety and depression affect insight in the non-clinical participants, but this is not so in the patients. As for the neurocognitive performance and its relation to SR and SC, we have been able to see that the explicative mechanisms are different for both groups of participants.

The study presents a series of limitations. The sample, although small, is representative of the persons with schizophrenia who attend sessions in the rehabilitation services, but not so of persons affected by schizophrenia, as older persons and women are under-represented. As for the group of healthy individuals, a paired sampling would have contributed to eliminating the influence of certain variables which should have been subjected to a statistical control. The use of the BCIS as the only instrument of measurement, and whose completion already requires an adequate level of reflection, also represents a limitation, so a complementary measure carried out by a clinician should be included in the evaluation of insight. As we have indicated, the absence of any measure of the patients' psychopathological level, as well as of their pharmacological treatment, which may influence their cognitive performance, are also limitations to be taken into account.

For future research, we note the need to consider cognitive insight as a general style of thought, beyond the psychiatric context in which it arose. This would also require the development of specific evaluation systems for the healthy population. A better clarification of the psychopathological variables associated with the improvement in cognitive insight and the change in the way of thinking would seem to be essential when taking into account the development of intervention programmes.
Beck, A. T., Epstein, N., Brown, G., \& Steer, R. A. (1988). An inventory for measuring clinical anxiety: Psychometric properties. Journal of Consulting and Clinical Psychology, 56(6), 893. https://doi.org/10.1037/0022006X.56.6.893

Beck, A. T., Steer, R., \& Brown, G. (1996). Beck Depression Inventory second edition Mannual. San Antonio, TX: The Psychological Corporation. 
Beck, A. T., \& Warman, D. M. (2004). Cognitive insight: Theory and assessment. In X. Amador \& A. David (Eds.), Insight and Psychosis: Awareness of Illness in Schizophrenia and Related Disorders (2nd Ed.) (79-87). Oxford University Press.

Benedet, M. J., \& Alejandre, M. A. (1998). TAVEC: Test de Aprendiraje $V$ erbal España-Complutense [Verbal Learning Test Spain-Complutense]. TEA.

Birulés, I., López-Carrilero, R., Cuadras, D., Pousa, E., Barrigón, M. L., Barajas, A., Lorente-Rovira, E., González-Higueras, F., Grasa, E., RuizDelgado, I., Cid, J., de Apraiz, A., Montserrat, R., Peláez, T., Moritz, S., The Spanish Metacognition Study Group, \& Ochoa, S. (2020). Cognitive Insight in First-Episode Psychosis: Changes during Metacognitive Training. Journal of Personalized Medicine, 10(4), 253. https://doi.org/10.3390/jpm10040253

Buchy, L., Czechowska, Y., Chochol, C., Malla, A., Joober, R., Pruessner, J., \& Lepage, M. (2010). Toward a model of cognitive insight in firstepisode psychosis: Verbal memory and hippocampal structure. Schizophrenia Bulletin, 36(5), 1040-1049. https://doi.org/10.1093/schbul/sbp015

Buchy, L., Hawco, C., Joober, R., Malla, A., \& Lepage, M. (2015). Cognitive insight in first-episode schizophrenia: Further evidence for a role of the ventrolateral prefrontal cortex. Schizophrenia Research, 166(1-3), 65-68. https://doi.org/10.1016/j.schres.2015.05.009

Carse, T., \& Langdon, R. (2013). Delusion proneness in nonclinical individuals and cognitive insight the contributions of rumination and reflection. Journal of Nervous and Mental Disease, 201(8), 659-664. https://doi.org/10.1097/NMD.0b013e31829c4fe7

Cohen, J. (1988). Statistical Power Analysis for the Behavioral Sciences (2nd. ed.). New York: Lawrence Earlbaum.

Colis, M. J., Steer, R. A., \& Beck, A. T. (2006). Cognitive insight in inpatients with psychotic, bipolar, and major depressive disorders. Journal of Psychopathology and Behavioral Assessment, 28(4), 242-249. https://doi.org/10.1007/s10862-005-9012-7

Dimaggio, G., Vanheule, S., Lysaker, P. H., Carcione, A., \& Nicolò, G. (2009). Impaired self-reflection in psychiatric disorders among adults: A proposal for the existence of a network of semi-independent functions. Consciousness and Cognition, 18(3), 653-664. https://doi.org/10.1016/i.concog.2009.06.003

Drake, R. J., Dunn, G., Tarrier, N., Bentall, R. P., Haddock, G., \& Lewis, S. W. (2007). Insight as a predictor of the outcome of first-episode nonaffective psychosis in a prospective cohort study in England. The Journal of Clinical Psychiatry, 68(1), 81-86. https://doi.org/10.4088/JCP.v68n0111

Engh, J. A., Sundet, K., Simonsen, C., Vaskinn, A., Lagerberg, T. V., Opjordsmoen, S., Friis, S. \& Andreassen, O. A. (2011). Verbal learning contributes to cognitive insight in schizophrenia independently of affective and psychotic symptoms. Progress in Neuro-Psychopharmacology and Biological Psychiatry, 35(4), 1059-1063. https://doi.org/10.1016/i.pnpbp.2011.02.021

Frith, C. D. (1995). La esquizofrenia: Un enfoque neuropsicológico cognitivo [Schizophrenia: A Cognitive Neuropsychological Approach]. Ariel.

García Guerrero, A., \& Lysaker, P. H. (2013). Socially naive self-appraisal moderates the relationship between cognitive insight and positive symptoms in schizophrenia. Schizophrenia Research, 143(1), 97-101. https://doi.org/10.1016/i.schres.2012.10.037

Giusti, L., Mazza, M., Pollice, R., Casacchia, M., \& Roncone, R. (2013). Relationship between self-reflectivity, theory of mind, neurocognition, and global functioning: An investigation of schizophrenic disorder. Clinical Psychologist, 17, 67-76. https://doi.org/10.1111/cp.12006

González-Blanch, C., Álvarez-Jiménez, M., Ayesa-Arriola, R., MartínezGarcía, O., Pardo-García, G., Balanzá-Martínez, V., Suárez-Pinilla, P. \& Crespo-Facorro, B. (2014). Differential associations of cognitive insight components with pretreatment characteristics in first-episode psychosis. Psychiatry Research, 215(2), 308-313. https://doi.org/10.1016/i.psychres.2013.12.003

Granholm, E., McQuaid, J.R., McClure, F.S., Auslander, L.A., Perivoliotis, D., Pedrelli, P., Patterson, T., \& Jeste, D. V. (2005). A randomized, controlled trial of cognitive behavioral social skills training for middleaged and older outpatients with chronic schizophrenia. American Journal of Psychiatry, 162(3), 520-529. https://doi.org/10.1176/appi.ajp.162.3.520. PMID: 15741469
Gutiérrez-Zotes, J. A., Valero, J., Cortés, M. J., Labad, A., Ochoa, S., Ahuir, M., Carlson, J., Bernardo, M., Cañizares, S., Escartín, G., Cañete, J., Gallo, P., \& Salamero, M. (2012). Spanish adaptation of the Beck Cognitive Insight Scale (BCIS) for schizophrenia. Actas Españolas de Psiquiatría, 40(1), 2-9.

Heaton, R., Chelune, G., Talley, J. L., Kay, G., \& Curtiss, G. (Eds.). (1993). Wisconsin Card Sorting Test Manual (revised and expanded). Odessa: Psychological assessment resources. Odessa, Florida: Psychological Assessment Resources.

Johns, L. C., \& van Os, J. (2001). The continuity of psychotic experiences in the general population. Clinical Psychology Review, 21(8), 1125-1141. https://doi.org/10.1016/s0272-7358(01)00103-9

Lezak, M. (1995). Neuropsychological assessment (3rd ed.). Oxford University Press.

Lincoln, T. M., Möbius, C., Huber, M. T., Nagel, M., \& Moritz, S. (2014). Frequency and correlates of maladaptive responses to paranoid thoughts in patients with psychosis compared to a population sample. Cognitive Neuropsychiatry, 19(6), 509-526. https://doi.org/10.1080/13546805.2014.931220

Lysaker, P. H., \& Buck, K. D. (2008). Insight and schizophrenia: Correlates, etiology and treatment. Clinical Schizophrenia \& Related Psychoses, 2(2), 147-154.

Moritz, S., Woodward, T. S., Whitman, J. C., \& Cuttler, C. (2005). Confidence in errors as a possible basis for delusions in schizophrenia. The Journal of Nervous and Mental Disease, 193(1), 9-16. https://doi.org/10.1097/01.nmd.0000149213.10692.00

Moritz, S., \& Woodward, T. S. (2006). The contribution of metamemory deficits to schizophrenia. Journal of Abnormal Psychology, 115(1), 15. https://doi.org/10.1037/0021-843X.15.1.15

Moritz, S., \& Woodward, T. S. (2007). Metacognitive training in schizophrenia: From basic research to knowledge translation and intervention. Current Opinion in Psycbiatry, 20(6), 619-625. https://doi.org/10.1097/YCO.0b013e3282f0b8ed

Nair, A., Palmer, E. C., Aleman, A., \& David, A. S. (2014). Relationship between cognition, clinical and cognitive insight in psychotic disorders: A review and meta-analysis. Schizophrenia Research, 152(1), 191-200. https://doi.org/10.1016/j.schres.2013.11.033

Nuechterlein, K. H., Barch, D. M., Gold, J. M., Goldberg, T. E., Green, M. F., \& Heaton, R. K. (2004). Identification of separable cognitive factors in schizophrenia. Schizophrenia Research, 72(1), 29-39. https://doi.org/10.1016/j.schres.2004.09.007

Orfei, M. D., Caltagirone, C., Cacciari, C., Assogna, F., \& Spalletta, G. (2011). The neuropsychological correlates of cognitive insight in healthy participants. Applied Cognitive Psychology, 25(6), 927-932. https://doi.org/10.1002/acp.1771

Orfei, M. D., Piras, F., Macci, E., Caltagirone, C., \& Spalletta, G. (2013). The neuroanatomical correlates of cognitive insight in schizophrenia. Social Cognitive and Affective Neuroscience, 8(4), 418-423. https://doi.org/10.1093/scan/nss016

Orfei, M. D., Spoletini, I., Banfi, G., Caltagirone, C., \& Spalletta, G. (2010). Neuropsychological correlates of cognitive insight in schizophrenia. Psychiatry Research, 178(1), 51-56. https://doi.org/10.1016/i.psychres.2009.05.013

Palmer, E. C., Gilleen, J., \& David, A. S. (2015). The relationship between cognitive insight and depression in psychosis and schizophrenia: $A$ review and metaanalysis https://doi.org/10.1016/i.schres.2015.05.032

Penney, D., Sauvé, G., Joober, R., Malla, A. K., \& Lepage, M. (2018). Establishing clinical cutoff values for the Beck Cognitive Insight Scale. Cognitive Therapy and Research, 1-11. https://doi.org/10.1007/s10608-018$\underline{9963-0}$

Pijnenborg, G. H., Van der Gaag, M., Bockting, C. L., Van der Meer, L., \& Aleman, A. (2011). REFLEX, a social-cognitive group treatment to improve insight in schizophrenia: Study protocol of a multi-center RCT. BMC Psychiatry, 11, 161-244X-11-161. https://doi.org/10.1186/1471244X-11-161

Rathee, R., Luhrmann, T. M., Bhatia, T., \& Deshpande, S. N. (2018). Cognitive insight and objective quality of life in people with schizophrenia and auditory hallucinations. Psychiatry Research, 259, 223-228. https://doi.org/10.1016/j.psychres.2017.09.032 
Ruiz-Vargas, J. M. (1987). Esquizofrenia: Un enfoque cognitivo [Schizophrenia: A Cognitive Approach7. Alianza Editorial.

Sanz, J., Perdigón, A., \& Vázquez, C. (2003). Adaptación española del Inventario para la depresión de Beck-II (BDI-II): 2. Propiedades psicométricas en población general [Spanish adaptation of the Beck-II Inventory for Depression (BDI-II): 2. Psychometric properties in the general population]. Clínica y Salud, 14(3), 249-280.

Sanz, J., \& Navarro, M. E. (2003). Propiedades psicométricas de una versión española del inventario de ansiedad de Beck (BAI) en estudiantes universitarios [Psychometric properties of a Spanish version of the Beck Anxiety Inventory (BAI) in university students]. Ansiedad y Estrés, 9(1), $59-84$.

Segarra, N., Bernardo, M., Gutiérrez, F., Justicia, A., Fernadez-Egea, E., Allas, M., Safont, G., Contreras, F., Gascón, J., Soler-Insa, P. A., Menchón, J. M., Junque, C. \& Keefe, R. S. E. (2011). Spanish validation of the brief assessment in cognition in schizophrenia (BACS) in patients with schizophrenia and healthy controls. European Psychiatry, 26(2), 6973. https://doi.org/10.1016/i.eurpsy.2009.11.001

Simón-Expósito, M. \& Felipe-Castaño, E. (2018). Cognitive insight, neurocognition and life skills in patients with schizophrenia. Psicothema, 30(3), 251-256. https://doi.org/10.7334/psicothema2018.12

Simón-Expósito, M. \& Felipe-Castaño, E. (2019). Effects of metacognitive training on cognitive insight in a sample of patients with schizophrenia. International Journal of Environmental Research and Public Health, 16(22), 4541. https://doi.org/10.3390/ijerph16224541

Sponheim, S. R., Jung, R. E., Seidman, L. J., Mesholam-Gately, R. I., Manoach, D. S., O’Leary, D. S., Ho, B. C., Andreasen, N. C., Lauriello,
J. \& Schulz, S. C. (2010). Cognitive deficits in recent-onset and chronic schizophrenia. Journal of Psychiatric Research, 44(7), 421-428. https://doi.org/10.1016/i.jpsychires.2009.09.010

Srivastava, K., \& Kumar, R. (2016). Cognitive insight and executive function in schizophrenia. SIS Journal of Projective Psychology \& Mental Health, 23(2), 106-114.

Van Camp, L., Sabbe, B., \& Oldenburg, J. (2017). Cognitive insight: A systematic review. Clinical Psychology Review, 55, 12-24. https://doi.org/10.1016/i.cpr.2017.04.011

Warman, D. M., Lysaker, P. H., \& Martin, J. M. (2007). Cognitive insigh and psychotic disorder: The impact of active delusions. Schizophrenia Research, 90(1-3), 325-333. https://doi.org/10.1016/j.schres.2006.09.011

Warman, D. M., \& Martin, J. M. (2006). Cognitive insight and delusion proneness: An investigation using the beck cognitive insight scale. Schizophrenia Research, 84(2-3), 297-304. https://doi.org/10.1016/i.schres.2006.02.004

Weintraub, M. J., \& Weisman de Mamani, A. (2015). Effects of sub-clinical psychosis and cognitive insight on psychological well-being: A structural equation model. Psychiatry Research, 226(1), 149-155. https://doi.org/10.1016/j.psychres.2014.12.039

Wells, A., \& Matthews, G. (1994). Self-consciousness and cognitive failure as predictors of coping in stressful episodes. Cognition \& Emotion, 8(3), 279-295. https://doi.org/10.1080/02699939408408942

Woodward, T. S., Moritz, S., Cuttler, C., \& Whitman, J. C. (2006). The contribution of a cognitive bias against disconfirmatory evidence (BADE) to delusions in schizophrenia. Journal of Clinical and Experimental Neuropsychology, 28(4), 605-617. https://doi.org/10.1080/13803390590949511 